\title{
A COMUNiCAÇÃo No PROCESSO dA hOSPITALIZAÇÃo do IMIGRANTE
} JAPONÉS

\author{
Rosa Yuka Sato Chubaci ${ }^{1}$ \\ Miriam Aparecida Barbosa Merighi
}

Chubaci RYS, Merighi MAB. A comunicação no processo da hospitalização do imigrante japonês. Rev Latino-am Enfermagem 2002 novembro-dezembro; 10(6):805-12.

A comunicação - verbal e não-verbal - no processo da hospitalização é um importante caminho para um novo olhar e agir dos profissionais de enfermagem. Partindo do pressuposto que a compreensão da doença e da hospitalização pode ser prejudicada pelo não entedimento da língua portuguesa, realizamos o presente estudo, que objetivou conhecer a importância da comunicação para o imigrante japonês durante o seu processo de hospitalização. Para desvelar a experiência vivida optamos pela pesquisa qualitativa com abordagem fenomenológica. Entrevistamos 17 pacientes imigrantes japoneses em um hospital na cidade de São Paulo. Resultados mostraram que a dificuldade com o idioma português interfere na compreensão da doença, do tratamento e no relacionamento com a equipe de saúde, fazendo suscitar o sentimento de insegurança, e que a cultura realmente exerce influência importante no comportamento e atitudes desses imigrantes japoneses em relação à doença e hospitalização.

DESCRITORES: migração internacional, comunicação, hospitalização

\section{COMMUNICATION DURING THE HOSPITALIZATION OF JAPANESE IMMIGRANT PATIENTS}

Communication - verbal or non-verbal - during hospitalization is an important tool to provide a new way of looking and acting to nursing professionals. Based on the consideration that the understanding about the disease and hospitalization can be impaired due to the difficulty in understanding the Portuguese language, the authors carried out the present study aiming at evaluating the importance of the communication during hospitalization. In order to unveil the experience of these subjects, the authors developed a qualitative investigation with a phenomenological approach. Authors interviewed 17 Japanese immigrants at a hospital in the city of São Paulo. Results showed that the difficulty in speaking Portuguese interfered in the patients' understanding about the disease, its treatment and the relationship with the health team, enhancing the feeling of insecurity and demonstrating that culture does play an important role on these patients' behavior and attitudes concerning the disease and hospitalization.

DESCRIPTORS: international migration, communication, hospitalization

\section{LA COMUNICACIÓN EN EL PROCESO DE LA HOSPITALIZACIÓN DEL INMIGRANTE JAPONÉS}

La comunicación - verbal y no-verbal - en el proceso de la hospitalización es un importante camino para una nueva observación y acción de los profesionales de la enfermería. A partir del supuesto de que la comprensión de la enfermedad y de la hospitalización puede ser perjudicada por el no entendimiento del idioma portugués, realizamos el presente estudio para el inmigrante japonés durante su proceso de hospitalización. Para desvelar la experiencia vivida optamos por la investigación cualitativa con abordaje fenomenológico. Fueron entrevistados 17 pacientes inmigrantes japoneses en un hospital de la ciudad de São Paulo. Los resultados mostraron que la dificultad con el idioma portugués interfiere en la comprensión de la enfermedad, tratamiento y en la relación con el equipo de salud del hospital, haciendo nacer el sentimiento de inseguridad. La cultura realmente ejerce una influencia importante en el comportamiento y las actitudes de esos inmigrantes japoneses en relación a la enfermedad y su hospitalización.

DESCRIPTORES: migración internacional, comunicación, hospitalización

\footnotetext{
${ }^{1}$ Mestre em enfermagem, Doutoranda em enfermagem, Bolsista da FAPESP, e-mail: chubaci@usp.br; ${ }^{2}$ Professor Associado, e-mail:
} lesami@ig.com.br. Escola de Enfermagem da Universidade de São Paulo 
INTRODUÇÃO

"Quando eu soltar a minha voz

Por favor entenda

Que palavra por palavra

Eis aqui uma pessoa se entregando"(1) $\ldots$.

O trecho dessa música reflete a importância da comunicação no relacionamento interpessoal no cotidiano de cada pessoa. As palavras, quando ditas, possuem significados, transmitem mensagens que não podem ser ignoradas, devem ser ouvidas e compreendidas, pois só assim pode-se estabelecer o início de uma boa comunicação.

A comunicação é um processo de compreender, compartilhar mensagens enviadas e recebidas, cuja mensagem e o modo como se dá seu intercâmbio exercem influências no comportamento das pessoas envolvidas, podendo ser verbal, por meio da linguagem escrita e falada, e não-verbal, por manifestações de comportamento não expressas por palavras ${ }^{(2)}$. É um recurso de intuição e de expressão, o meio pela qual o ser humano expressa a sua maneira de $\operatorname{ser}^{(3)}$.

Assim sendo, a comunicação verbal e não-verbal no processo de hospitalização é um importante caminho para um novo modo de olhar e agir dos profissionais de enfermagem. Afinal, "o enfermeiro é um educador e a educação é, sobretudo, comunicação"(2).

O profissional de enfermagem é o membro da equipe de saúde com maior contato com o paciente durante o seu processo de hospitalização. Nesse sentido, podemos enfatizar a importância desse profissional em decodificar, decifrar e perceber o significado da mensagem que o paciente envia; só assim poderá estabelecer um plano de cuidado adequado e coerente com as suas necessidades ${ }^{(4)}$. Além disso, a comunicação efetiva fará com que o profissional de enfermagem possa ajudar o paciente a conceituar seus problemas, a enfrentá-los, a visualizar a experiência vivida e até auxiliá-lo a encontrar novos padrões de comportamento ${ }^{(4)}$.

Essa comunicação efetiva, no entanto, pode ser prejudicada quando existe a barreira do idioma. Um estudo realizado sobre a hospitalização de imigrantes japoneses nos Estados Unidos constatou que esses têm problemas com o idioma, necessitando de intérpretes para serem compreendidos e, normalmente, não questionam a equipe de saúde sobre sua doença e tratamento, refletindo em suas atitudes as influências culturais ${ }^{(5)}$.
A história da evolução humana mostra aproximação cada vez mais intensa entre os povos de variadas raças e etnias, tornando-se comum a existência de várias culturas convivendo e relacionando-se na vida cotidiana. Observa-se a importante influência da cultura na comunicação verbal e principalmente não-verbal das pessoas de diferentes grupos étnicos ${ }^{(4)}$. O grupo étnico é um grupo social com um determinado status, inserido em um grande sistema social, sendo que cada grupo possui, em sua base, traços complexos de religiosidade, língua, sexo, estilo de vida, ancestralidade, raça e características físicas $^{(6)}$

Nesse contexto, podemos notar que o processo saúde-doença pode ser melhor entendido quando o consideramos como parte da experiência cultural do indivíduo, pois a cultura exerce influência nas percepções, emoções, crenças, na imagem corporal, na alimentação, atitudes em relação à doença, dor, entre outros. Além dos fatores individuais (idade, gênero, personalidade, inteligência e experiência), os educacionais e os sócioeconômicos influenciam no cuidado cultural do indivíduo ou grupo social ${ }^{(7)}$.

Além disso, durante o processo de hospitalização o paciente é afastado de seu ambiente familiar, das atividades sociais e profissionais, passando a vivenciar um novo cotidiano.

Frente a essas considerações julgamos ser necessário desenvolver estudos com pacientes de diferentes culturas e etnias.

O interesse pelo tema da hospitalização do imigrante japonês surgiu durante a trajetória profissional da primeira autora em um hospital da cidade de São Paulo, ao perceber que havia muitos pacientes de diferentes origens étnicas. Dentre esses, destacava-se o imigrante japonês, que talvez pela origem da autora referenciada, acabou sendo vivenciado mais profundamente. Soma-se a esse fato a experiência pessoal de ter tido um membro da família doente e o relato de algumas dificuldades vivenciadas por ele durante a hospitalização, fazendo com que aumentassem as inquietações quanto à assistência de enfermagem oferecida para esses imigrantes japoneses.

Sentimos, então, a necessidade de compreender o significado da hospitalização para esse grupo específico, tema esse que culminou na dissertação de mestrado da primeira autora deste estudo ${ }^{(8)}$. Tal estudo com os imigrantes japoneses revelou, dentre os resultados, a importância da comunicação no processo de 
hospitalização do imigrante japonês, temática essa que apresentaremos neste artigo.

\section{CAMINHO METODOLÓGICO E FILOSÓFICO}

O desafio em compreender o sentido da hospitalização para o imigrante japonês fez com que investigássemos as suas experiências. Para tanto, após a revisão dessa temática, percebemos que uma pesquisa qualitativa com abordagem fenomenológica poderia contribuir para a elucidação dos nossos propósitos.

A fenomenologia é capaz de compreender e explicitar os processos do ser - entendido como a maneira pela qual algo torna-se presente, manifesto, conhecido para o ser humano - na existência humana, como "deixar e fazer ver por si mesmo aquilo que se mostra, tal como se mostra a partir de si mesmo"(9). Como referencial filosófico, não procura o quê do objeto, mas o como: como se demonstra, como vivencia o mundo a partir da existência $^{(9)}$.

A construção fenomenológica tem a tarefa de esclarecer, a partir da temporalidade, a própria historicidade, na qual a história da presença estará encoberta de forma vulgar, sendo necessário interpretá-lo ${ }^{(10)}$.

A construção existencial da historicidade, portanto, é conduzida por meio da interpretação do ser em sua trajetória, a sua presença e análise de cura, que ocorre no seu tempo, ou seja, na sua temporalidade. A partir do modo de ser desse ente, que existe historicamente, nasce a possibilidade existenciária de uma abertura e de uma apreensão explícita da história ${ }^{(10)}$.

Esse referencial filosófico ${ }^{(9-10)}$ vem ao encontro com o mundo-vida do imigrante japonês que, na trajetória de sua vida, se deparou com a facticidade de ter vivido numa época de dificuldades em seu país de origem, sendo que a maior parte desses imigrantes optou pela imigração em busca de uma vida melhor.

Uma parte da história da imigração no Brasil foi constituída pelos imigrantes japoneses, cujo processo imigratório, desde 18 de junho de 1908, foi marcado, em sua maioria, pelo tormento, hostilidade, desafio e dor. Ao chegarem, os japoneses encontraram uma realidade totalmente diferente daquela que Ihes fora informada em seu país, desiludindo-se profundamente. Além disso, a diversidade da língua, costumes, alimentação, clima e as doenças tropicais em algumas regiões foram os principais entraves para a adaptação do imigrante japonês.
Por meio da fenomenologia heideggeriana buscamos compreender o sujeito imigrante na facticidade de uma internação.

\section{A PESQUISA RUMO À COMPREENSÃO DO FENÔMENO}

Definimos como sujeitos da pesquisa os imigrantes japoneses residentes no Brasil, desconsiderando a idade, sexo, estado civil ou religião. Definimos ainda, como outros critérios de seleção dos sujeitos: a condição da internação, excluindo aqueles que não poderiam fornecer uma descrição da experiência vivida; a permanência de internação por mais de cinco dias, por considerar que o discurso teria maior riqueza pelo fato de terem experienciado a hospitalização por maior tempo. Optamos, ainda, por um hospital sem ligações com a colônia japonesa por considerar que a facticidade de uma internação, muitas vezes, impede o sujeito de escolher um hospital com características japonesas.

Os princípios éticos dessa pesquisa foram baseados na Resolução 196/96 sobre as diretrizes e normas regulamentadoras de pesquisa em seres humanos $^{(11)}$. Tivemos, então, a participação voluntária, após assinatura do termo de Consentimento Livre e Esclarecido.

O número de sujeitos foi determinado a partir do momento que os discursos tornaram-se repetitivos na elucidação do fenômeno. Durante o período de abril a novembro de 1998, foram entrevistados 22 sujeitos e, dentre esses, 17 foram considerados, pois continham mais significados para nós, enquanto pesquisadoras. Apenas uma entrevista foi concedida em português e as demais em japonês.

Utilizamos a seguinte questão norteadora: faleme sobre os seus sentimentos de estar experienciando a doença e a hospitalização. Com essa indagação, pudemos conhecer e compreender o significado da hospitalização do imigrante japonês a partir da perspectiva de quem a vivenciou.

Para analisar os dados efetuamos as etapas de redução e compreensão do fenômeno. Nessas etapas as unidades de significados - aspectos essenciais do discurso, que possuem um significado para o pesquisador - são reescritas na busca de maior clareza, procurando expressar o pensamento do sujeito articulado no 
discurso ${ }^{(12)}$. Após várias leituras, identificamos as unidades de significado, selecionando as informações mais relevantes e essenciais dos depoimentos. Essa busca das unidades de significado foi feita de acordo com a nossa perspectiva, enquanto pesquisadoras, focalizando o fenômeno que está sendo pesquisado. O passo seguinte foi a seleção das informações, contidas nas unidades de significado do discurso, quanto aos aspectos comuns que emergiram com maior destaque; isto é, buscamos dentro do depoimento a similaridade dos conteúdos (convergências). Reunimos trechos da entrevista considerados relevantes para a discussão do assunto, que se referiam a um mesmo conteúdo e aspectos.

Posteriormente, ao concentrarmo-nos de forma atenta e rigorosa sobre cada grupamento, foi possível realizar a identificação de oito temas, caracterizando, assim, a estrutura geral do fenômeno. Os temas identificados foram: relembrando o passado; enfrentando dificuldade para comunicar-se; vivenciando a separação; sentindo necessidade de um bom cuidado; sentindo-se impotente para enfrentar situações difíceis; sentindo necessidade de suporte familiar; buscando conforto na religião e sentindo gratidão.

Dentre esses temas que representam a experiência da hospitalização vivenciada pelos imigrantes japoneses, destacamos, neste momento, o tema desvelado "Enfrentando dificuldade para comunicar-se" que retrata a importância da comunicação no processo da hospitalização do imigrante japonês. Desta forma, apresentamo-lo, a seguir, com os subtemas que o compuseram.

\section{ENFRENTANDO DIFICULDADE PARA COMUNICAR-SE}

Como já mencionamos anteriormente, a internação é uma situação que leva o imigrante japonês a enfrentar o desafio em direção à recuperação, em um ambiente estranho ao seu cotidiano. Além da adaptação à rotina do hospital e ao tratamento, o imigrante japonês mostrou que existe outra barreira: a comunicação. Vários deles afirmaram ser o idioma a sua grande dificuldade.

Desta forma, do tema dificuldade para comunicar-se originaram-se os seguintes subtemas: dificuldade para compreender a doença; dificuldade para compreender o tratamento; dificuldade para relacionar-se com a equipe de saúde; sentindo desconfiança; sentindo necessidade da ajuda dos familiares; sofrendo por não poder comunicar-se; sentindo segurança quando consegue comunicar-se e percebendo o incômodo e o arrependimento por não falar o português. Subtemas esses que serão apresentados a seguir.

Dificuldade para compreender a doença

Alguns imigrantes japoneses têm dificuldades para dominar a língua portuguesa; outros nem chegam a aprendê-la. Essa situação faz com que se sintam inseguros, pois a dificuldade com o idioma é um empecilho para questionarem sobre a doença e compreenderem o que é explicado pelos profissionais de saúde. A situação agrava-se ainda mais quando a doença é complicada. As explicações contêm palavras técnicas, o que torna ainda mais difícil o entendimento, mesmo para aqueles que conseguem entender um pouco o idioma. Nessas condições, um deles manifesta a vontade de estar em um lugar onde pudesse compreender tudo o que é dito.

...Quando a gente tem doenças complicadas fica difícil de entender por causa do idioma. Quando estou numa situação assim, fico com vontade de estar num hospital japonês. É melhor quando dá para falar na própria língua, se me falarem em português, eu não entendo nada..

... eu falo português, pois já estou há muito tempo, só não consigo entender direito quando usam palavras difíceis para explicar o que tenho e quando respondo, não sei se me entenderam...

Dificuldade para compreender o tratamento

Alguns imigrantes japoneses sentem que o idioma dificulta-lhes entender os procedimentos aos quais são submetidos durante o tratamento. Não conseguem questionar e tampouco compreender as explicações ou instruções dadas, pois muitas vezes essas são feitas com palavras técnicas, piorando ainda mais a situação.

...Hoje fui fazer tomografia e tive dificuldades para entender as instruções na hora do exame, imaginei que fosse para inspirar e expirar...

...quando o médico vem conversar comigo eu desconfio que ele esteja falando sobre isso ou aquilo, mas não tenho certeza. Aqui no hospital, devido às palavras técnicas, o entendimento é pior ainda...

Outros referem-se à necessidade de saber mais 
sobre os procedimentos a que foram ou serão submetidos. A dúvida em relação a alguns cuidados é proveniente da comunicação ineficiente.

...Estou com as mãos pretas, ninguém me falou o que aconteceu com a minha mão. Nem as enfermeiras contaram porque aconteceu isso com a minha mão. Como não sei falar direito, não pergunto...

...Penso que deveriam avisar qualquer mudança que haja, como, por exemplo, o horário dos remédios. Não tenho como perguntar, não dá para perguntar...

Observa-se o interesse desses imigrantes japoneses sobre o tratamento ao qual estão sendo submetidos. Assim, mais uma vez, sentem-se limitados pela barreira do idioma.

Dificuldade para relacionar-se com a equipe de saúde

A maioria desses imigrantes japoneses passa a não conversar com as pessoas ao seu redor porque entendem pouco ou quase nada do que as enfermeiras ou os médicos lhes dizem, principalmente quando usam terminologias médicas. Um deles disse sentir que as pessoas acabam se afastando dele por não compreenderem o que fala ou, até mesmo, considerá-lo um paciente difícil.

...As pessoas que vêm aqui não conversam comigo, trazem uma coisa, depois outra, mas, no entanto, não conversam comigo, deve ser porque somos desconhecidos. Eu também nem penso em conversar com eles. Sabe, nem conseguiria entender direito e nem escutar direito. Precisam conversar alto comigo...

...Sempre tento falar que meu português é ruim e que não entendo o que eles, os médicos, me falam. Devem me achar uma paciente chata...

Um deles relata, ainda, a vontade de compreender a conversa com o médico, para saber sobre seu tratamento; para tanto desejaria contar com a ajuda da enfermeira, mas percebe que essa não tem disponibilidade para isso. Verbaliza que, se o médico escrevesse o que quer Ihe falar, poderia facilitar o entendimento, já que alguém poderia ajudá-lo a traduzir.

...Às vezes não entendo o que os médicos falam e as enfermeiras não têm tempo de explicar...

...quando o médico fala comigo não entendo o que ele quer dizer, gostaria até de pedir para que escreva, mas acabo não pedindo...

Outros imigrantes japoneses tentam conversar de alguma forma, gesticulam com as mãos, para serem compreendidos. Sentem que, com o tempo, algumas enfermeiras entendem melhor o que tentavam pedir.

...Aqui eu tenho problemas com o idioma, quando não consigo falar gesticulo com as mãos. As pessoas tentam me entender...

...No começo as enfermeiras tiveram dificuldades comigo, mas agora que estou há 22 dias parece que se acostumaram comigo. Algumas enfermeiras entendem melhor o que eu falo... Tem gente que parece me entender instintivamente...

A dificuldade com o idioma reflete-se no relacionamento com a equipe de saúde, complicando a comunicação entre todos. Os imigrantes japoneses deste estudo demonstraram a necessidade de manter um contato com a equipe profissional, para que, de alguma forma, possam ser entendidos.

Sentindo desconfiança

Apesar da importante ajuda que recebe da família, um imigrante japonês diz perceber que o filho não está preparado para traduzir a conversa com o médico, desconfiando que as informações que recebe são incompletas.

...Meu filho me acompanha, mas sei que o japonês que ele sabe não é o suficiente para explicar a minha situação no hospital. Fico me questionando se ele está traduzindo corretamente ou não. Fico desconfiada se está certo mesmo...

Outro imigrante japonês, ao tentar comunicar-se com o pouco que sabe do idioma português, desconfia se realmente entenderam o que quis dizer. $\mathrm{O}$ mesmo acontece quando tem dúvidas sobre o que entendeu da conversa que teve com o médico. A desconfiança surge, também, como conseqüência da dúvida em relação às instruções dadas durante os procedimentos.

...Tento me expressar com as poucas palavras que sei em português, acham graça dizendo que falo "japorguês", eu acho que falei certo, mas quando respondem vejo que entenderam errado. Fico desconfiada se realmente me entenderam ou não. O idioma é realmente um grande problema...

...Senti-me inseguro no exame, não sabia se estava fazendo certo..

Observa-se que esses sujeitos tentam comunicarse por sentirem necessidade de entender e serem entendidos, mas essa tentativa é, muitas vezes, em vão. Assim, acabam deduzindo o conteúdo das conversas. No entanto, sentem-se inseguros e desconfiados pois não têm como confirmá-lo. Como já salientado, a partir do 
momento em que ocorre a dificuldade de comunicação, diminui a confiança na assistência recebida.

Sentindo necessidade da ajuda de familiares

Uma das formas encontradas pela maioria dos imigrantes japoneses, ao deparar-se com a dificuldade do idioma, é buscar a ajuda dos familiares para serem interlocutores nessa comunicação. Desse modo, a presença da família quase sempre ameniza a dificuldade com o idioma, fazendo com que se sintam melhores e mais tranqüilos durante a hospitalização.

...Meu filhos me acompanham aqui no hospital, por eu não entender o português. Tenho cinco filhos que se revezam para ficar comigo. Não consigo entender nada do que o médico fala. Sinto-me mais tranqüila quando eles estão por perto...

Ao receber a ajuda da família como interlocutor, esses imigrantes japoneses encontram uma alternativa para contornar a dificuldade com o idioma. Dessa forma, podem compreender melhor sua doença e tratamento, melhorando sua comunicação com a equipe de saúde.

\section{Sofrendo por não poder comunicar-se}

Para vários imigrantes japoneses, o sofrimento faz-se presente ao sentirem a angústia e a tristeza de estarem impossibilitados de conversar com as pessoas, impedindo-os de expressar o que sentem.

...Só o idioma que é problema. Sabe, não consigo dizer o que estou pensando... não consigo nem dizer o que quero aqui dentro (hospital). Isto me trás angústia, penso como seria feliz se soubesse falar português...

...O pior é quando queremos perguntar coisas importantes, não dá para falar...Fico adivinhando o que o médico falou comigo, isso me deixa um pouco tenso...

A dificuldade com o idioma, faz com que a internação torne-se um problema para muitos imigrantes japoneses, atribuem ao idioma português a responsabilidade pelos vários episódios desagradáveis ocorridos durante a hospitalização. $O$ fato de não poderem detalhar o que sentem prejudica-os, ainda mais, na comunicação com a equipe de saúde, o que os impossibilita de receberem dados mais completos em relação à saúde.

...Sabe, quando sinto dor eu falo "dói", mas existem várias formas de dor, o que dói em agulhada, a que sufoca, tem várias formas de dor. Não consigo falar essas coisas detalhadas, acabo só falando que dói...
Sentindo segurança quando consegue comunicar-se

Ao deparar-se com a barreira da comunicação, um imigrante japonês manifestou a vontade de estar em um hospital onde pudesse conversar com as pessoas e saber detalhes sobre seu tratamento, o que faria com que se sentisse mais seguro. Coincidentemente, o fato do médico ser de descendência japonesa fez com que um deles se sentisse mais tranqüilo, ficando mais motivado, pois o médico poderia entender melhor seus sentimentos.

...Quando eu fui internado aqui, aconteceu algo muito bom, o responsável por meu tratamento é um nikkey, entendendo bem os meus sentimentos, sou muito agradecido por isso. É como se o meu sangue começasse a circular de novo, senti-me bem tranqüilo por conta disso...

A felicidade de poder conversar em japonês é percebida durante a entrevista quando alguns sujeitos relataram poder expressar minuciosamente seus pensamentos.

...Como estou feliz em conversar em japonês com você. Posso falar do jeito que estou pensando, é muito bom, sinto-me feliz mesmo...

Ao mostrar as vantagens e a felicidade por poder conversar em japonês, observa-se que para esses imigrantes japoneses a comunicação é um fator importante para sua tranqüilidade dentro do hospital, pois podem colaborar e participar conscientemente de seu tratamento.

Percebendo o incômodo e o arrependimento por não falar português

Ao vivenciar os problemas causados pela dificuldade de comunicação durante a hospitalização, vários imigrantes japoneses perceberam-se incomodados por não falar o idioma português, arrependendo-se por não tê-lo aprendido antes.

...Só o idioma que é problema. Sabe, não consigo dizer o que estou pensando, penso então que deveria ter aprendido antes, agora me arrependo disso, mas nesta fase da vida não consigo mais aprender...

Vários deles tentam apresentar os prováveis motivos que os impediram de aprender o português, tentando justificar a dificuldade com o idioma.

...Convivi sempre com os japoneses, os meus filhos me ajudavam, então não consegui aprender português...

...Quando eu era pequena meus pais diziam: não precisava aprender português porque voltariamos logo para o Japão. Além disso só usávamos o Japonês para nos comunicar em casa... 
Percebe-se que, ao terem dificuldades com o idioma, os imigrantes japoneses desse estudo mostraram que essa situação é perturbadora. Tal deficiência afeta o seu emocional, trazendo angústia, tristeza e ansiedade. Ao citarem os motivos que justificam essa dificuldade, os sujeitos encontram uma razão para se desculparem por não terem aprendido o idioma português.

\section{CONSIDERAÇÕES FINAIS}

Os resultados do estudo mostraram que, para grande parte dos imigrantes japoneses, a compreensão do processo da doença e da hospitalização é prejudicada pela dificuldade da comunicação. A compreensão só é desvelada por meio da linguagem, que é feita pelo pronunciamento do discurso, sendo essa a articulação da compreensibilidade ${ }^{(9)}$.

Dessa forma, percebe-se que os imigrantes japoneses possuem inúmeras dificuldades pelo fato do idioma ser uma barreira, impedindo-os de manter uma comunicação efetiva com a equipe de saúde, dificultando, assim, o relacionamento. Conseqüentemente, passam a ter dificuldades para compreender a sua doença e o tratamento ao qual estão sendo submetidos, levando-os ao sofrimento por não poderem expressar o que sentem.

Essa situação é contornada, em parte, pela ajuda dos filhos. Porém, percebe-se que essa ajuda é dada não só no hospital, mas ao longo de toda as suas vidas. Tal fato fez com que se acomodassem e não aprendessem português. Essa situação pode ser entendida como um cuidado em que a preocupação retirou o "cuidar" do outro, substituindo-o em suas ocupações e tornando-o dependente ${ }^{(9)}$.

É interessante notar que somente quando experienciam esse tipo de problema, em um momento difícil de sua vida, os imigrantes passam a sentir-se incomodados, dizendo-se arrependidos por não conseguirem entender o idioma. Ao mesmo tempo em que se sentem afetados pelo problema da comunicação, também percebem que a enfermagem e os demais profissionais da equipe de saúde sentem dificuldade para prestar um cuidado mais eficiente e adequado por causa do idioma, pois o relacionamento interpessoal fica prejudicado.

Esse estudo mostrou, também, que o imigrante japonês tem as suas falas permeadas pela influência cultural, possuindo algumas características comportamentais próprias. A começar pelo idioma japonês, que prevalece como sua língua principal e única, ainda nos dias de hoje.

As primeiras gerações de imigrantes sempre foram, em sua grande maioria, etnocêntricas - acreditam que a sua cultura, raça e o país de onde vieram constituem o centro do mundo -, talvez por uma questão de sobrevivência em ambientes tão hostis. Ao tentar refazer a sua história, uma vez que a imigração faz com que haja um rompimento do seu laço com suas origens, o imigrante japonês procura reescrever sua experiência à luz de valores e tradições que são parte do seu ser.

O fato desses imigrantes japoneses não questionarem sobre a sua doença e tratamento foi percebida em relação à equipe de saúde, mas em várias entrevistas os imigrantes manifestaram vontade de saber e participar mais dos procedimentos ao qual estavam sendo submetidos. Talvez essa situação possa ser explicada pelo fato da entrevista ter sido feita em japonês, dando mais abertura para o sujeito poder expressar os sentimentos vivenciados. Do mesmo modo, o fato da entrevistadora não pertencer ao quadro pessoal do hospital foi, também, uma condição estimuladora na obtenção dos dados.

Foi possível, ainda, perceber que muitas falas foram marcadas pela exposição de alguns conceitos culturais japoneses, como a auto-restrição (enryo), autocontrole em suportar situações angustiantes e/ou aflitivas (gaman) e o conformar-se com a situação vivida (shoganai). O enryo, por exemplo, pode ser percebido no estudo quando o imigrante tem dúvidas sobre algum procedimento e não pede esclarecimento, pelo receio de incomodar a equipe; prefere, então, conformar-se com a situação (shoganai), suportando, desta forma o seu sofrimento (gaman). Verificou-se, com freqüência, a verbalização do sentimento de shoganai, ou seja, o conformar-se com a situação, permitindo-nos perceber, com as nossas experiências vividas enquanto profissional de enfermagem, que o imigrante japonês manifesta esse sentimento com maior freqüência do que outros pacientes. Parece que isso faz com que, de alguma forma, se sintam protegidos das situações adversas às quais estão expostos durante a hospitalização.

Compreendemos que o imigrante japonês tem sérias dificuldades para ser entendido pelos outros, por não conseguir se expressar em português em razão de 
alguns hábitos culturais específicos, assim, chamamos atenção para a falsa impressão que eles podem transmitir de que tudo está em ordem. Ao serem entrevistados no idioma japonês, demonstraram que, por trás de seu jeito sereno de ser, escondiam, muitas vezes, a ansiedade e o interesse pelo cuidado de sua saúde, o desejo de que o olhar dos familiares, equipe de saúde e, principalmente, da enfermagem estivesse voltado para eles.

Dessa forma, o estudo mostrou que a comunicação verbal e não-verbal é imprescindível para o relacionamento interpessoal no processo de hospitalização do imigrante japonês. O profissional de enfermagem deve estar atento para o significado da mensagem que é transmitida pelo paciente, pois, assim, poderá oferecer um cuidado mais efetivo, centrado nas necessidades dele. Devemos lembrar, também, que pequenos gestos, um olhar podem ser tão ou mais significativos que as palavras.

\section{REFERÊNCIAS BIBLIOGRÁFICAS}

1. Gonzaguinha. Sangrando. In: O talento de Gonzaguinha [CD]. Brasil: Emi-Odeon; 1994.

2. Stefanelli MC. Comunicação com o paciente: teoria e ensino. $2^{\mathrm{a}}$ ed. São Paulo (SP): Robe; 1993.

3. Martins J, Bicudo MAV. A pesquisa qualitativa em psicologia: fundamentos e recursos básicos. São Paulo (SP): Moraes; 1989.

4. Silva MJP. Comunicação tem remédio: a comunicação nas relações interpessoais em saúde. $5^{a}$ ed. São Paulo: Gente; 1996.

5. Shiba G, Oka R. Japanese americans. In: Lipson JG, Dibble SL, Minarik PA, editors. Culture \& nursing care: a pocket guide. California: Regents; 1996. p. 180-90.

6. Spector R. Culture, ethnicity and nursing. In: Potter P, Perry A, editors. Fundamental of nursing: concepts, process and practice. St. Louis: Mosby; 1993. p. 95-116.

7. Helman CG. Cultura, saúde e doença. $2^{a}$ ed. Porto Alegre (RS): Artes Médicas; 1994.

8. Chubaci RYS. A experiência da hospitalização do imigrante japonês. [dissertação]. São Paulo (SP): Escola de Enfermagem/USP; 1999.

9. Heidegger M. Ser e tempo. Petrópolis (RJ): Vozes; 1997a. Parte I (Coleção Pensamento Humano).

10. Heidegger M. Ser e tempo. Petrópolis (RJ): Vozes; 1997b. Parte II (Coleção Pensamento Humano).

11. Ministério da Saúde (BR). Diretrizes e normas regulamentadoras de pesquisa em seres humanos. Brasília: Conselho Nacional de Saúde; 1997.

12. Giorgi A. Phenomenology and psyschological research. Pittsburg: Duschesne University Press; 1985. 